\title{
Measurements of Calcium Transients in the Soma, Neurite, and Growth Cone of Single Cultured Neurons
}

\author{
Stephen R. Bolsover ${ }^{\star}$ and Ilan Spector $\dagger$ \\ *Department of Physiology, University College, London, London WC1E 6BT, England, and \\ fDepartment of Anatomical Sciences, Health Sciences Center, State University of New York at Stony Brook, Stony \\ Brook, New York 11794
}

\begin{abstract}
Voltage-gated changes in cytosolic free calcium ion concentration were measured in single, differentiated cells of mouse neuroblastoma clone N1F-115 using the calcium-sensitive dye arsenazo III (AIII). In cells bathed in normal medium containing $10 \mathrm{mM}$ calcium, the changes in AIII absorbance during a single action potential indicated an increase of $1.4 \mathrm{nM}$ in cytosolic calcium. When $10 \mathrm{~mm}$ tetraethylammonium (TEA) was added to the bath, the action potential became prolonged and the change in cytosolic calcium increased to $3.9 \mathrm{~nm}$. Under these conditions, repetitive stimulation at $0.5 \mathrm{~Hz}$ or faster caused a gradual decline in the amplitude and duration of the action potential and a gradual decline of the change in cytosolic calcium associated with each action potential. The amplitude of the prolonged after-hyperpolarization (AHP) that follows the action potential was found to reflect the magnitude of the change in cytosolic calcium. An action potential elicited in the cell soma caused an increase in cytosolic calcium in the soma, neurite, and growth cone regions of a single cell, indicating that the membrane of all three regions possesses voltage-gated calcium channels. Estimation of calcium flux per unit area of membrane suggests a distinct topographical organization of calcium channels. Calcium channel densities in the growth cone and cell soma regions are similar and significantly higher than that in the neurite.
\end{abstract}

The plasma membrane of nerve cells contains calcium channels that subserve different functions (for revicws, sce Campbell, 1983; Hille, 1984), but the spatial distribution of these channels over the neuronal membrane is not known. Several studies of invertebrate cells have suggested that calcium currents contribute significantly to the total membrane current in the soma and in the presynaptic tcrminal, but are negligible in the axon (Kado, 1973; Llinás et al., 1981; Meves and Vogel, 1973; Miledi and Parker, 1981; Stockbridge and Ross, 1984). These studies and the fundamental role of calcium in transmitter release (Katz, 1969) have led to the widely accepted view that calcium channels are concentrated in the soma and presynaptic terminals of all neurons (for a review, see Hagiwara and Byerly, 1981). Attempts to localize calcium currents in regions other than the cell soma of mammalian neurons have been limited to intracellular recordings of calcium action potentials in dendrites (Llinás and Sugimori, 1980) and to indirect recordings of calcium action potentials in neurites and growth cones of cultured nerve cells using extracellular electrodes or optical methods (Anglister et al., 1982; Dichter and Fischbach, 1977; Grinvald and Farber, 1981; Willard, 1980). However, these studies are difficult to

\footnotetext{
Received July 26, 1985; revised Nov. 18, 1985; accepted Dec. 18, 1985.

We thank Drs. J. E. Brown, P. DeWeer, and G. D. Fischbach for helpful criticism. 'T his work was supported by National Institutes of Health Grants NS 20857 to S.R.B. and NS 22028 to I.S.

Correspondence should be addressed to Dr. Spector at the above address.

Copyright (C) 1986 Society for Neuroscience $0270-6474 / 86 / 071934-07 \$ 02.00 / 0$
}

interpret because they cannot give precise information about the behavior of a local region of the cell or detect the presence of active calcium channels that do not contribute significantly to the action potential. To examine the spatial distribution of voltage-gated calcium entry in the neuronal cell membrane, we used the calcium indicator dye arsenazo III (AIII) (Brown et al., 1975). This dye presents two important advantages. First, it can diffuse rapidly inside the cell (R. F. Rakowski, personal communication), thereby allowing measurements of changes in cytosolic calcium concentration $\left(\left[\mathrm{Ca}^{2+}\right]_{i}\right)$ in all regions of a single neuron. Second, the response is directly proportional to the calcium concentration change. Therefore, the changes in optical absorbance on adding calcium to a volume of dye (e.g., the cell soma) are independent of the spatial distribution of the added calcium (Smith and Zucker, 1980). To date, this technique has been used to examine changes in $\left[\mathrm{Ca}^{3+}\right]_{\mathrm{i}}$ in the cell soma region of a variety of neuronal preparations (Ahmed and Connor, 1979; Smith and Zucker, 1980; Smith et al., 1983) and in the presynaptic terminal region of invertebrate cells (Miledi and Parker, 1981; Stockbridge and Ross, 1984), but no studies have examincd changes in $\left[\mathrm{Ca}^{2+}\right]_{\mathrm{i}}$ in all regions of a single neuron.

Clonal lines of the C1300 mouse neuroblastoma provide a highly suitable mammalian preparation to study localization of calcium entry in various regions of the cell, to examine the establishment of this localization during development, and to relate this entry to different neuronal functions. In these cells calcium has been shown to play an important role as a charge carrier across the membrane (Fishman and Spector, 1981; Moolenaar and Spector, $1979 \mathrm{a}, \mathrm{b}$ ) and as an intracellular messenger that regulates a variety of neuronal functions, such as the permeability of the cell membrane to various ions (Moolenaar and Spector, 1979a, b; Yellen, 1982), neurotransmitter secretion (Nirenberg et al., 1983), and growth cone movement (Anglister et al., 1982). In the present study we used AIII to measure $\left[\mathrm{Ca}^{2+}\right]_{1}$ transients resulting from a single action potential in the cell soma, neurite, and growth cone of dimethylsulfoxide (DMSO)differentiated cells of clone N1E-115.

\section{Materials and Methods}

N1E-115 cells were grown and induced to differentiate as described previously (Moolenaar and Spector, 1978). Experiments were performed on cells grown on polylysine-coated glass coverslips for 7-16 d after replating in growth medium containing $2 \%$ DMSO. The coverslip was placed in a chamber mounted on the stage of a compound microscope and superfused with a solution containing $130 \mathrm{~mm} \mathrm{NaCl}, 5.5 \mathrm{mM} \mathrm{KCl}$, $10 \mathrm{mM} \mathrm{CaCl}_{2}, 1 \mathrm{~mm} \mathrm{MgCl}, 25 \mathrm{~mm}$ glucose, and $20 \mathrm{~mm}$ HEPES, $\mathrm{pH}$ 7.4. Where noted, $10 \mathrm{~mm}$ tetraethylammonium chloride (TEA) was added without other adjustments. The cell soma was impaled with a single micropipette containing $30 \mathrm{~mm}$ AIII, $5 \mathrm{~mm} 3-(N$-morpholino) propane sulfonic acid (MOPS), and $100 \mathrm{mM} \mathrm{KCl}, \mathrm{pH}$ 7.8. This micropipette was used to pass current and to record voltage. AIII was injected 


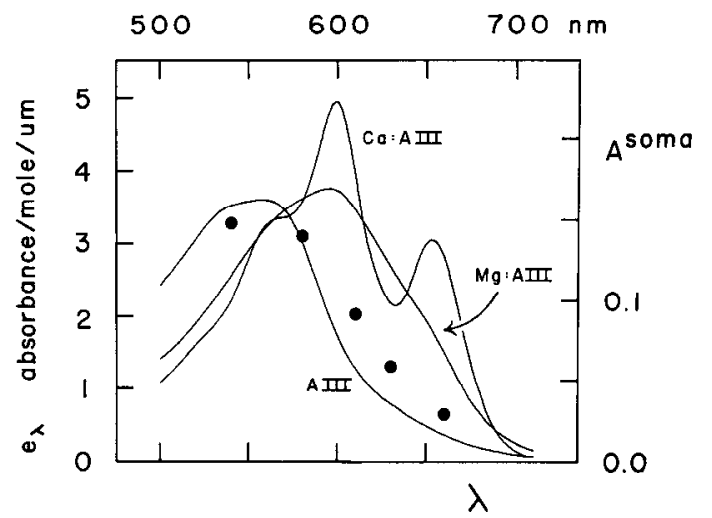

Figure 1. In vitro and in vivo absorbance spectra of arsenazo III. Continuous lines, In vitro absorbance spectra of AIII in different media: $A I I I$, free; $C a: A I I I$, bound to calcium; $M g: A I I I$, bound to magnesium. Filled circles, Absorbance of AIII in a soma of a N1E-115 cell bathed in normal $\mathrm{Na}^{+}$medium containing $10 \mathrm{mM} \mathrm{Ca}^{2+}$ and $10 \mathrm{~mm}$ TEA. The absorbance increase produced by injecting AIII solution, to an estimated total concentration of $0.8 \mathrm{~mm}$, into the cell soma was measured at five different wavelengths. The soma pathlength was $56.5 \mu \mathrm{m}$. Abscissa, Wavelength in $\mathrm{nm}$; left ordinate, absorptivity values of the in vitro spectra; right ordinate, absorbance of the injected cell soma (see text for details).

by applying pressure (1-5 psi) to the back of the pipette to a final absorbance of $0.02-0.04$ at $660 \mathrm{~nm}$. To allow for the dye to diffuse throughout the cell, measurements were made at least 10 min after dye injection. Comparison of signals from the soma, neurite, and growth cone was not made until at least $30 \mathrm{~min}$ after dye injection. Light from a quartz-halogen source was limited to a single wavelength band by interference filters (10 $\mathrm{nm}$ full-width, half-maximum) and focused onto the cell by a microscope condenser. Light passing through the cell was collected by a long-working-distance objective and measured with a photodiode. Light reaching the photodiode was limited by two pairs of razor blades that could be adjusted to define a specific rectangular aperture in the back focal plane of the objective. The aperture was adjusted under visual control to frame a cell soma, a neurite, or a growth cone. Action potentials were elicited in the cell soma by depolarizing current pulses superimposed on a steady hyperpolarizing current or by anode break stimulation from the resting potential. The optical signal was lowpass-filtered using a four-pole Bessel filter with a time constant of 30 msec. No signal averaging was used. Experiments were performed at room temperature $\left(21-24^{\circ} \mathrm{C}\right)$. Results are given as means \pm SEM.

\section{Calibration of AIII}

Absorbance spectra of AIII were measured in the following solutions: free AIII, magnesium AIII (Mg:AIII), and calcium AIII (Ca:AIII). Measurements were carried out in cuvettes of $200 \mu \mathrm{m}$ pathlength using a DMS 90 spectrophotometer (Varian Corp., Palo Alto, CA). All solutions contained $1 \mathrm{~mm}$ sodium AIII, $10 \mathrm{~mm}$ HEPES, and $120 \mathrm{~mm} \mathrm{KCl}$ and one of the following: $60 \mathrm{mM} \mathrm{KCl}$ for the AIII solution; $20 \mathrm{mM} \mathrm{MgCl}_{2}$ for the $\mathrm{Mg}$ :AIII solution; and $20 \mathrm{mM} \mathrm{CaCl}$ for the Ca:AIII solution. The $\mathrm{pH}$ was adjusted to 7.5 with $\mathrm{KOH}$. Blanks contained the corresponding salt and buffer concentrations. Figure 1 shows the absorbance spectra of free AIII, Mg:AIII, and Ca:AIII. The spectrum of the dye in a cell, measured at five wavelengths, is depicted by the data points. Specific absorptivity values $(e)$ in absorbance units $\times \mathrm{M}^{-1} \times \mu \mathrm{m}^{-1}$ for AIII, Mg:AIII, and Ca:AIII at 540 and $660 \mathrm{~nm}$ were

$$
\begin{aligned}
& e_{540}^{\text {AIII }}=3.52 \pm 0.03 ; \\
& e_{660}^{\text {AIII }}=0.37 \pm 0.01 \\
& e_{580}^{\mathrm{AgIII}}=2.55 \pm 0.03 \text {; } \\
& e_{\mathrm{G} \text { : AIII }}=1.50 \pm 0.02 \\
& e_{540}^{\text {ca:AII }}=2.22 \pm 0.03 \text {; } \\
& e_{660}^{\mathrm{Ca} A \mathrm{AIII}}=2.82 \pm 0.04
\end{aligned}
$$

As shown in Figure 1, the absorbance of AIII inside the cell was intermediate between the in vitro absorbance spectrum of free AlII and that of $\mathrm{Mg}$ :AIII and was quite distinct from the absorbance spectrum of $\mathrm{Ca}$ : AIII. This indicates that AIII in the cytosol is present as a mixture of free AIII and a Mg:AIII complex, and that if a Ca:AIII complex is present, its concentration is below detection. This result further indicates that the cytosolic free calcium concentration is much lower than $2 \mu \mathrm{M}$, which is the dissociation constant $\left(K_{d}\right)$ for Ca:AIIl under these conditions (Brown and Rydqvist, 1981).

The fraction of the total intracellular AIII present as free dye $R=$ [AIII]/([AIII] + [Mg:AIII]) can be calculated from the optical absorbance at any two wavelengths at which AIII absorbs light. Using 540 and $660 \mathrm{~nm}$

$$
R=\frac{e_{540}^{\mathrm{Mg} A \mathrm{AII}}-a \cdot e_{660}^{\mathrm{Mg} A \mathrm{AIII}}}{a\left(e_{660}^{\mathrm{AIII}}-e_{650}^{\mathrm{MIDAII}}\right)-e_{540}^{\mathrm{AIII}}+e_{540}^{\mathrm{M} \cdot \mathrm{AIII}}}
$$

where $e$ denotes the specific absorptivity measured in a defined solution in vitro, and $a$ the measured intracellular absorbance at $540 \mathrm{~nm}$ divided by the measured intracellular absorbance at $660 \mathrm{~nm}$. In nine cells, $R$ was found to be $0.75 \pm 0.03$. Using this value and the dissociation constant $\left(K_{\mathrm{d}}\right)$ for Mg:AIII, it is possible to calculate the cytosolic free magnesium concentration in N1E-115 cells provided the resting intracellular $\mathrm{pH}$ is known, since the $K_{\mathrm{d}}$ for $\mathrm{Mg}$ :AIII is a function of $\mathrm{pH}$ (Baylor et al., 1982). Moolenaar et al. (1984) have found the resting intracellular pH of N1E-115 cells to be 7.24 , which yields a $K_{\mathrm{d}}$ for $\mathrm{Mg}$ : AIII of $2.0 \mathrm{mM}$. Using our measurements of $R=0.75$, we calculated the cytosolic free magnesium concentration in N1E- 115 cells to be 0.67 mM.

The optical absorbance of intracellular AIII is linearly proportional to both the intracellular concentration of AIII and the optical pathlength. The total intracellular concentration of AIII can therefore be calculated as

$$
\text { [AIII }]+[\mathrm{Mg}: \mathrm{AIII}]=A_{660} /\left(e_{660}^{\mathrm{mix}} \cdot \text { pathlength }\right)
$$

where $A_{660}=$ measured absorbance at $660 \mathrm{~nm}$, and $e_{660}^{\operatorname{mix}}=R \cdot e_{660}^{\text {AII }}+$ $(1-R) \cdot e_{56}^{\mathrm{M} A \mathrm{AIII}}$. The optical pathlength through different regions of a single cell was measured by focusing first on the upper surface and then on the lower surface of the cell using Hoffman modulation contrast optics. From these measurements, the mean total intracellular concentration of AIII was calculated to be $1.5 \pm 0.5 \mathrm{~mm}$.

Considering that the intracellular AIII is present as a mixture of free AIII and Mg:AIII, an increase in cytosolic free calcium concentration $\left(\left[\mathrm{Ca}^{2+}\right]_{i}\right)$ will cause the formation of a Ca:AIII complex that will be reflected by an increase of optical absorbance at 610 and $660 \mathrm{~nm}$, the maxima of the absorbance spectrum for Ca:AIII (Fig. 1). In this work we have chosen to use the absorbance changes at $660 \mathrm{~nm}$, because this wavelength was found to give the best signal-to-noise ratio.

Quantitative determination of changes in cytosolic free calcium concentration based on the absorbance changes of AIII depends on a host of factors (Ahmed and Connor, 1979; Smith and Zucker, 1980). Nonetheless, under the conditions that (1) the fractional changes of [AIII] and [Mg:AIII] are small and can be ignored; (2) the fraction of total free intracellular AIII $(R)$ reequilibrates and remains constant following the formation of Ca:AIII; and (3) $\left[\mathrm{Ca}^{2+}\right]_{i}$ is low, so that Ca:AIII does not contribute significantly to the total absorbance spectrum, the change of intracellular free calcium concentration will be given by

$$
\Delta\left[\mathrm{Ca}^{2+}\right]_{\mathrm{i}}=\frac{K_{\mathrm{d}}^{\text {ca:AIII }} \cdot \Delta A_{660} \cdot e_{660}^{\text {mix }}}{R \cdot A_{660} \cdot \Delta e_{660}^{\mathrm{Ca}}}
$$

where $\Delta\left[\mathrm{Ca}^{2+}\right]_{\mathrm{i}}$ is the change of intracellular free calcium concentration; $K_{d}^{\text {ca:Aml }}$ is the dissociation constant for the Ca:AIII complex and is taken to be $2 \mu \mathrm{M}$, the value appropriate for $1 \mathrm{~mm}$ AIII (Brown and Rydqvist, 1981); $\Delta A_{660}$ is the change of absorbance at $660 \mathrm{~nm}$; and $\Delta e_{660}^{\mathrm{Ca}}=$ $e_{660}^{\text {Ca:AIII }}-e_{660}^{\text {mix. }}$

\section{Results}

\section{AIII responses in the cell soma during a single action potential}

In normal medium containing $1.8 \mathrm{~mm}$ calcium the action potential of neuroblastoma cells consists of a fast $\mathrm{Na}^{+}$component followed by a small $\mathrm{Ca}^{2+}$ component (Moolenaar and Spector, 1978). Under these conditions, the $\mathrm{Ca}^{2+}$ current is very small (Moolenaar and Spector, 1979b), and the light signal during a 
A

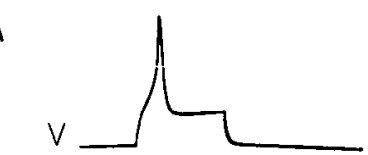<smiles>COc1ccccc1</smiles>

$A_{660}^{\text {soma }}$

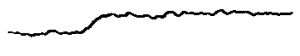

$I \triangle A=3 \times 10^{-4}$
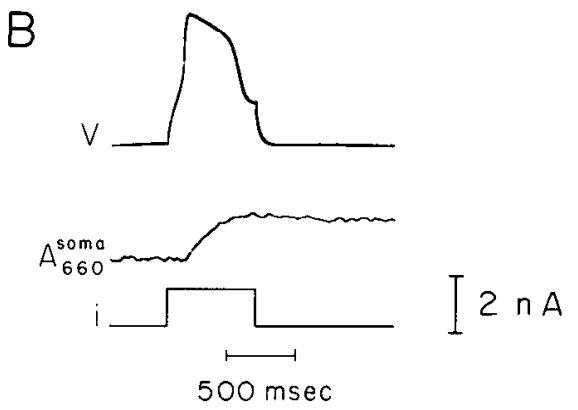

Figure 2. Intracellular calcium transients associated with a single action potential in the soma of a N1E-115 cell bathed in normal $\mathrm{Na}^{+}$ medium containing $10 \mathrm{mM} \mathrm{Ca}^{2+}$ before $(A)$ and after $(B)$ addition of 10 mM TEA to the bath. Here and Figure 3, trace $V$ represents the action potential elicited by a depolarizing current pulse applied at a hyperpolarized membrane potential of $-90 \mathrm{mV}$; trace $A_{660}^{\text {soma }}$ represents the optical absorbance at $660 \mathrm{~nm}$. An upward deflection of the optical signal indicates an increase in cytosolic $\left[\mathrm{Ca}^{2+}\right]$. The lowermost trace in $B$ is the current pulse. Note, in $B$, the prolongation of the action potential and the larger rise of the cytosolic $\left[\mathrm{Ca}^{2+}\right.$. The absorbance calibration bar indicates that $\Delta A_{660}=3 \times 10^{-4}$ and is equivalent to $\Delta A_{660} / A_{660}=$ $7 \times 10^{-3}$.

single action potential is expected to be too small to be resolved without the use of signal averaging. However, in media containing elevated $\mathrm{Ca}^{2+}$, the contribution of $\mathrm{Ca}^{2+}$ currents to the action potential is enhanced (Moolenaar and Spector, 1979a, b), and as a result it is possible to examine $\left[\mathrm{Ca}^{2+}\right]_{\mathrm{i}}$ transients without signal averaging. Figure $2 A$ shows an action potential elicited in a cell soma injected with AIII and bathed in medium containing $10 \mathrm{mM} \mathrm{Ca}^{2+}$ (upper trace), and the simultaneously recorded optical signal (lower trace). It can be seen that the optical signal exhibits an upward deflection, which represents an increase in the absorbance of light by the cell soma at 660 $\mathrm{nm}$. A smaller downward deflection with a similar time course was recorded at $540 \mathrm{~nm}$, with a ratio of $\Delta A_{540}^{\text {soma }} / \Delta A_{660}^{\text {soma }}=$ $-0.68 \pm 0.08$ (three cells). These optical changes are consistent with binding of calcium to AIII and therefore reflect an elevation of $\left[\mathrm{Ca}^{2+}\right]_{i}$ (Brown et al., 1975). They are inconsistent with a nonspecific effect such as a change in light scattcring, which should also be seen at other wavelengths where the absorbance of the dye is great (Fig. 1), but no light signal could be reliably detected at other wavelengths. As shown in Figure $2 A,\left[\mathrm{Ca}^{2+}\right]$ begins to increase at the onset of the action potential upstroke, reaches a steady level at the termination of the action potential, and does not return to baseline over a time course of seconds. In five cells, $\Delta A_{660}^{\mathrm{soma}} / A_{660}^{\mathrm{soma}}$, the fractional change of absorbance at $660 \mathrm{~nm}$ during the action potential, was $(1.8 \pm 0.4) \times 10^{-3}$, and the increase in free calcium concentration was calculated to be $1.4 \pm 0.3 \mathrm{~nm}$ using equation 3 . This value is somewhat lower than values estimated for bullfrog sympathetic neurons, $10 \mathrm{~nm}$ (Smith et al., 1983), and rat dorsal root ganglion cells, $18 \mathrm{nM}$ (Neering and McBurney, 1984).

That the absorbance change was due to $\mathrm{Ca}^{2+}$ influx through
A
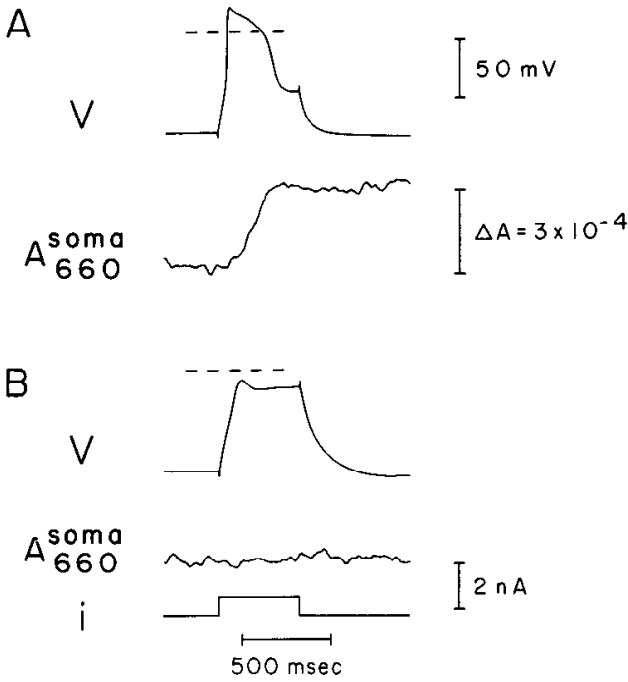

Figure 3. Effects of cobalt ions on the action potential and the calcium signal in a N1E- 115 cell bathed in normal $\mathrm{Na}^{+}$medium containing 10 $\mathrm{mM} \mathrm{Ca}{ }^{2+}$ and $10 \mathrm{mM}$ TEA. Recordings of the action potential and optical absorbance at $660 \mathrm{nM}$ before $(A)$ and after $(B)$ addition of $10 \mathrm{mM} \mathrm{Co}^{2+}$ to the bath. Note, in $B$, the complete suppression of the increase in cytosolic $\left[\mathrm{Ca}^{2+}\right]$.

voltage-gated calcium channels, and was not an artifact of current injection or of membrane depolarization, is indicated by the following observations. First, no absorbance changes were observed during an action potential before injection of AIII into the cytosol. Second, after injection of AIII no absorbance changes were observed during hyperpolarizing current pulses or during depolarizations that did not elicit an action potential. Third, when $10 \mathrm{~mm}$ TEA was added to the bath to suppress potassium currents that normally counteract the inward $\mathrm{Ca}^{2+}$ currents (Moolenaar and Spector, 1979b), both the action potential duration and the amplitude of the absorbance change increased markedly (Fig. $2 B$ ). In TEA-treated cells, $\Delta A_{660}^{\text {soma }} / A_{660}^{\text {soma }}$ was $(4.8 \pm 0.4) \times 10^{-3}$ (nine cells), and the increase in $\left[\mathrm{Ca}^{2+}\right]_{i}$ was calculated to be $3.9 \pm 0.3 \mathrm{nM}$. However, the maximum rate of change of $A_{660}^{\text {soma }}$ remained essentially unaltered in the presence of TEA; thus $\left[\mathrm{Ca}^{2+}\right]_{i}$ reached a maximum later, immediately before the termination of the TEA-modified action potential (Fig. 2B). Finally, as shown in Figure 3, the large absorbance change recorded during the TEA-modified action potential was completely eliminated by application of the calcium antagonist $\mathrm{Co}^{2+}(10 \mathrm{~mm})$, which severely reduced the amplitude of the action potential (Spector ct al., 1973). This effect was reversible on removal of $\mathrm{Co}^{2+}$.

\section{Relationship between intracellular calcium transients and $A H P$}

In many cell types, an increase in $\left[\mathrm{Ca}^{2+}\right]_{\mathrm{i}}$ causes an increase in $\mathrm{K}^{+}$permeability (Meech, 1978). In N1E-115 cells, Moolenaar and Spector (1979b) identified a slow, TEA-insensitive, $\mathrm{K}^{+}$current that is dependent on extracellular calcium and is blocked by calcium antagonists. They suggested that this slow $\mathrm{K}^{+}$current is activated by a calcium influx that occurs during the action potential, and is responsible for the prolonged AHP that follows an action potential. According to their model, enhanced $\mathrm{Ca}^{2+}$ entry should increase the amplitude and duration of the AHP. To test this hypothesis, action potentials were elicited by anodal break stimulation from the resting membrane potential, and the amplitude of the AHP that followed each action potential was compared with the amplitude of the absorbance changes. Because the resting membrane potential is between -35 and -55 $\mathrm{mV}$ and the reversal potential of the AHP is between -75 and 


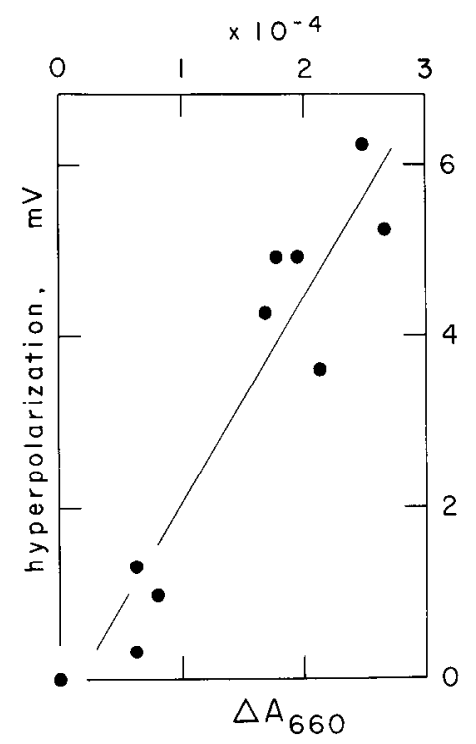

Figure 4. Plot of the AHP that follows an action potential versus the absorbance change at $660 \mathrm{~nm}\left(\Delta \boldsymbol{A}_{660}\right)$. The action potential was elicited by anode break stimulation of varying intensity from a resting potential of $-53 \mathrm{mV}$ in medium containing $10 \mathrm{mM} \mathrm{Ca}^{2+}$ and $10 \mathrm{~mm}$ TEA. The amplitude of the AHP was graded with the calcium signal during the action potential. Line fitted by linear regression.

$-85 \mathrm{mV}$ (Moolenaar and Spector, 1979a), AHP amplitudes of up to about $6 \mathrm{mV}$ will have little effect on the driving force for the AHP. As illustrated in Figure 4, under these zero external current conditions, the change in $\left[\mathrm{Ca}^{2+}\right]_{i}$ and the AHP amplitude were positively correlated over this limited range. A similar correlation was found in all cells studied (six cells). Thus, for these small increases of cytosolic calcium over the resting level, the $\mathrm{Ca}^{2+}$-dependent $\mathrm{K}^{+}$conductance can be regarded as a linear function of $\left[\mathrm{Ca}^{2+}\right]_{i}$. This result is consistent with the behavior of $\mathrm{Ca}^{2+}$-dependent $\mathrm{K}^{+}$channcls incorporated into planar lipid bilayers (Moczydlowski and Latorre, 1983).

\section{Intracellular calcium transients during posttetanic hyperpolarization}

One of the other roles attributed to the $\mathrm{Ca}^{2+}$-dependent $\mathrm{K}^{+}$ currents is to underlie the posttetanic hyperpolarization present in many neurons. It has been proposed that the persistence of the AHP for seconds following a train of action potentials is due to a summation of $\left[\mathrm{Ca}^{2+}\right]_{i}$ that enters during each action potential and that the kinetics of the posttetanic hyperpolarization directly reflects the kinetics of the $\left[\mathrm{Ca}^{2+}\right]_{\mathrm{i}}$ transient (Smith et al., 1983; Stockbridge and Ross, 1984). Figure 5 clearly shows that the progressive increase in the $\left[\mathrm{Ca}^{2+}\right]_{\text {i }}$ signal during a train of 15 action potentials elicited by $1 \mathrm{~Hz}$ stimulation is indeed due to a summation of $\left[\mathrm{Ca}^{2+}\right]_{1}$ that enters during each action potential. However, it can also be seen that there is a gradual decline in the amplitude and duration of the successive action potentials and that the summation of the optical signal is nonlinear, with a marked depression in the response to the second impulse. Thus, the increase in cytosolic calcium during the action potential train reaches a peak level of only $24 \mathrm{~nm}$. In the four cells studied, $\Delta A_{660}^{\text {soma }}$ of the second of a pair of action potentials $1 \mathrm{sec}$ apart was $63 \pm 4 \%$ of the control, and the duration of the second action potential was $70 \pm 8 \%$ of the control. When action potentials were $2 \mathrm{sec}$ apart, $\Delta A_{660}^{\mathrm{soma}}$ and the duration of the second action potential were $79 \pm 4 \%$ and $84 \pm 7 \%$ of the control, respectively. Only when repetitive stimulation was applied at a rate of $0.2 \mathrm{~Hz}$ or less did the $\left[\mathrm{Ca}^{2+}\right]_{\mathrm{i}}$ change associated with each action potential and the action potential duration fail

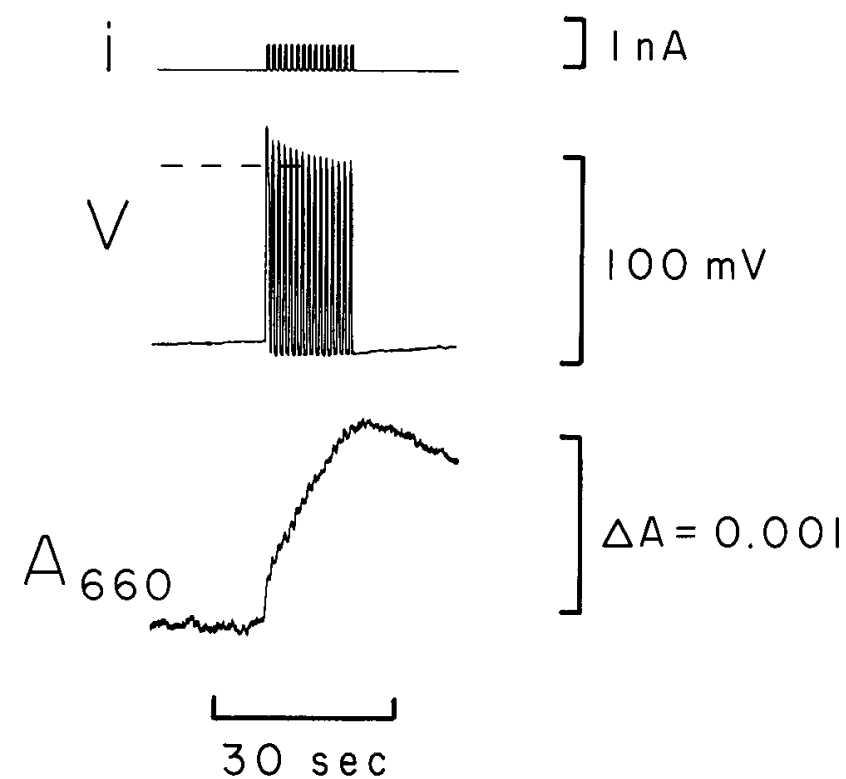

Figure 5. Intracellular calcium transients associated with a train of action potentials in the soma of a N1E-115 cell bathed in normal $\mathrm{Na}^{+}$ medium containing $10 \mathrm{~mm} \mathrm{Ca}^{2+}$ and $10 \mathrm{~mm}$ TEA. The action potential train was elicited by repetitive stimulation at $1 \mathrm{~Hz}$. Uppermost trace (i), The injected current; middle trace ( $V$ ), the membrane potential; lowest trace $\left(A_{660}\right)$, the absorbance of the cell soma to light of $660 \mathrm{~nm}$. Note the gradual decline in the amplitude and duration of the action potential, and the progressively smaller increase of intracellular calcium associated with each action potential. Note also the persistence of the AHP following the action potential train.

to decline. These results demonstrate that, at least in the presence of high extracellular calcium plus TEA, repetitive stimulation at a rate of $0.5 \mathrm{~Hz}$ or more causes a gradual decline in the amplitude and duration of the action potential and a nonlinear summation of the $\left[\mathrm{Ca}^{2+}\right]_{i}$ that enters during successive action potentials. However, in all cases the AHP undershoot reached a peak value of about $-89 \mathrm{mV}$, which was maintained throughout the action potential train. This value, which is virtually identical with the equilibrium potential for $\mathrm{K}^{+}$(Moolenaar and Spector, 1979a), began to decline very slowly only after the end of the train, concomitant with the $\left[\mathrm{Ca}^{2+}\right]_{i}$ signal. This result supports the contention that the long duration of the posttetanic hyperpolarization directly reflects a prolonged elevation of $\left[\mathrm{Ca}^{2+}\right]_{i}$ (Smith et al., 1983).

\section{Localization of voltage-gated calcium transients in different regions of a single cell}

In order to directly measure the voltage-gated calcium transients in different regions of a single cell, we elicited an action potential in the cell soma by a depolarizing current pulse, and monitored separately the optical absorbance of AIII at $660 \mathrm{~nm}$ inside the soma $\left(A_{660}^{\text {soma }}\right)$, the neurite $\left(A_{660}^{\text {neurite }}\right)$, and the growth cone $\left(A_{660}^{\text {s.cone }}\right)$ by limiting the light reaching the photodiode to a rectangular aperture that framed one of the three regions (see Fig. 6). The results of such an experiment are shown in Figure 6 (right panel). It can be seen that all three regions exhibit an increase in $\left[\mathrm{Ca}^{2+}\right]_{i}$ during the soma-evoked action potential, but that the magnitude of the increase is different in the three regions. The largest absorbance change was obtained in the cell soma, a slightly smaller signal was obtained from the growth cone, and the smallest signal from the neurite. In seven cells, the absorbance change in the growth cone was not significantly different from the $a b-$ sorbance change in the cell soma $\left(\Delta A_{660}^{\text {sone }} / \Delta A_{660}^{\text {soma }}=0.84 \pm 0.25\right)$. However, the absorbance change in the neurite was significantly smaller $\left(\Delta A_{660}^{\text {nearite }} / \Delta A_{660}^{\text {soma }}=0.49 \pm 0.17\right)$. These results demon- 


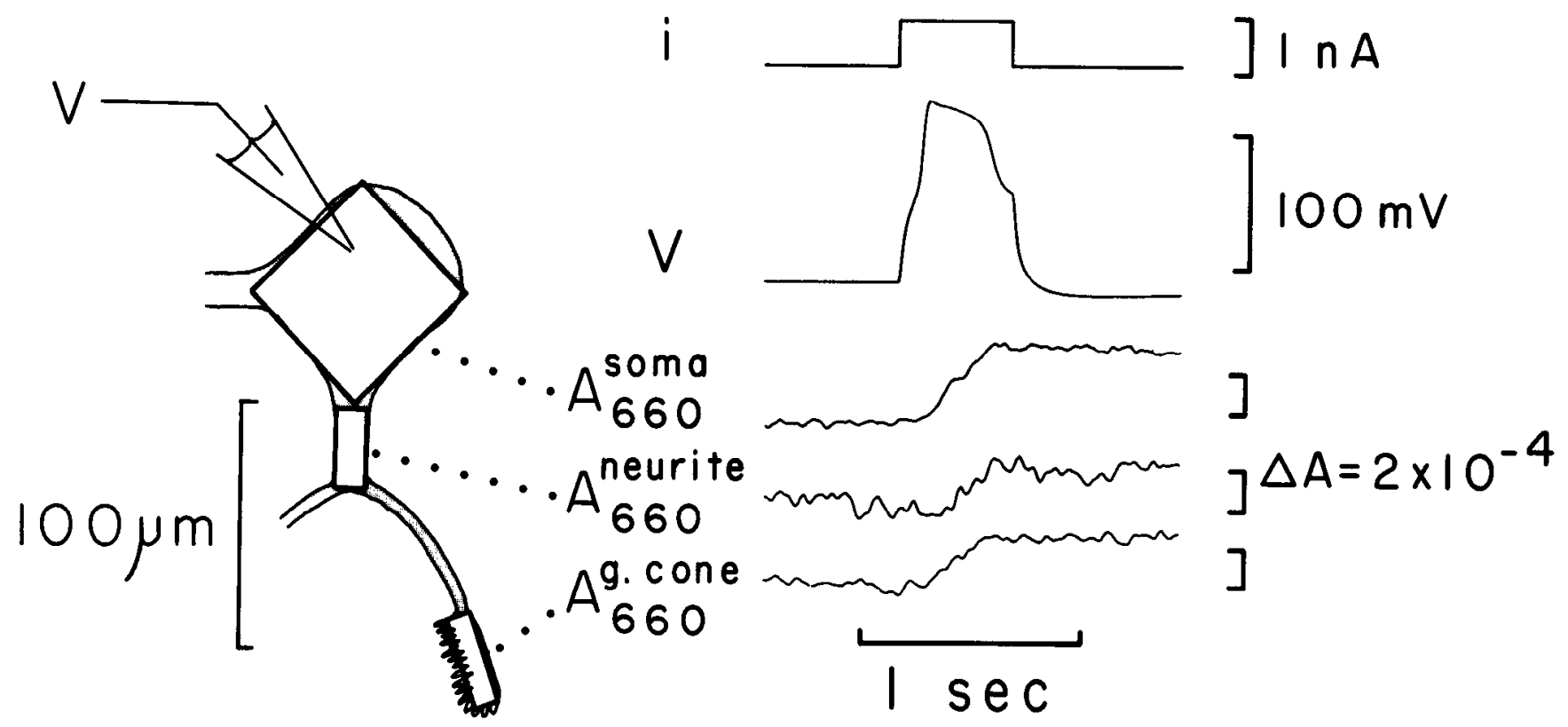

Figure 6. Right, Recordings of absorbance changes at $660 \mathrm{~nm}$ in the soma, neurite, and growth cone of a single N1E-115 cell during an action potential elicited in the cell soma. The cell was bathed in normal $\mathrm{Na}^{+}$medium containing $10 \mathrm{mM} \mathrm{Ca}^{2+}$ and $10 \mathrm{~mm}$ TEA. The uppermost trace (i) represents the current pulse; the second trace $(V)$, the membrane potential; the three lower traces, absorbance changes to light at 660 nm in the soma $\left(A_{660}^{\text {soma }}\right)$, neurite $\left(A_{660}^{\text {neurite }}\right)$, and growth cone $\left(A_{660}^{\text {gcone }}\right)$. Light reaching the photodiode was adjusted to a defined rectangular aperture that framed each of the three regions. The action potential shown was recorded in the soma during absorbance measurements in the soma. Absorbance changes in the neurite and growth cone were measured during a similar action potential elicited by identical stimulation. The sketch, left, shows the horizontal dimensions of the cell, the position of the micropipette used to pass current and record voltage, and the three rectangular apertures in the back focal plane of the objective that defined the light reaching the photodiode. The light pathlengths through the cytosol were $48 \mu \mathrm{m}$ (soma), $13 \mu \mathrm{m}$ (neurite), and $5 \mu \mathrm{m}$ (growth cone).

strate that voltage-gated calcium entry and, therefore, a calcium current, do occur in all three regions. In several experiments the pathlength through the cell was measured to be $48 \pm 6 \mu \mathrm{m}$ (10 cells) at the soma, $11 \pm 1 \mu \mathrm{m}$ (three cells) at the neurite, and $5 \pm 1 \mu \mathrm{m}$ (four cells) at the growth cone. If we assume a uniform intracellular concentration of AIII and $\mathrm{Mg}^{2+}$, then the absorbance change at $660 \mathrm{~nm}\left(\Delta A_{660}\right)$ is proportional to the product of the change in intracellular free calcium concentration $\Delta\left[\mathrm{Ca}^{2+}\right]_{i}$ and the pathlength. Thus, although the values of $\Delta A_{660}$ in the soma and growth cone were similar, $\Delta\left[\mathrm{Ca}^{2+}\right]_{\text {i }}$ during an action potential, averaged over the total pathlength, may rise to much higher levels in the flatter growth cone than in the soma. Similarly, despite the low value of $\Delta A_{660}$ in the neurite, an increase of $\left[\mathrm{Ca}^{2+}\right]_{i}$ during an action potential may be significant because of the small pathlength relative to that of the soma.

\section{Discussion}

In addition to demonstrating the feasibility of combining electrophysiological techniques and direct measurements of changes in the cytosolic calcium concentration in a single mammalian neuron, our study addresses several points pertaining to the properties and localization of voltage-gated calcium channels.

Previous work in molluscan neurons using the AIII technique has helped to resolve some problems concerning the properties of calcium currents (Ahmed and Connor, 1979; Gorman and Thomas, 1980; Smith and Zucker, 1980). For example, although it was widely accepted that the primary effect of TEA was to block the voltage-gated $\mathrm{K}^{+}$current and thereby prolong the action potential, it has not been clear whether the enhanced $\mathrm{Ca}^{2}$ । current that is observed in the presence of TEA is due to a direct stimulatory effect of TEA on calcium channels. Ahmed and Connor (1979) have shown that it is the prolongation of the action potential by external application of TEA that is respon- sible for the increased calcium influx during an action potential. Our results in N1E-115 cells demonstrate a similar effect. The initial rate at which $\left[\mathrm{Ca}^{2+}\right]_{i}$ rises at the onset of an action potential is not changed by TEA; rather, because of the prolongation of the action potential, the total $\left[\mathrm{Ca}^{2+}\right]_{i}$ change is considerably enhanced in the presence of TEA. Furthermore, we have found that the increase in $\left[\mathrm{Ca}^{2+}\right]_{1}$ during the TEA-modified action potential reaches a maximum immediately before the repolarization phase that terminates the action potential; thus, the rate of increase of cytosolic calcium is abruptly halted by the repolarization phase. These results are consistent with a model according to which the termination of the TEA-modified action potential is due to activation of $\mathrm{Ca}^{2+}$-gated $\mathrm{K}^{+}$channels by raised cytosolic calcium (Alvarez-Leefmans and Miledi, 1980; Neering and McBurney, 1984; Ross and Stuart, 1978). The possibility that the primary trigger for repolarization of the TEAmodified action potential is voltage inactivation of $\mathrm{Ca}^{2+}$ channels is rather unlikely because the rate of increase of cytosolic calcium, and therefore the inward calcium current, hardly declines during the action potential. Another consequence of the activation of $\mathrm{Ca}^{2+}$-gated $\mathrm{K}^{+}$channels by raised cytosolic calcium in N1E-115 cells is the prolonged AHP that follows the action potential (Moolenaar and Spector, 1979a). Our results show that the amplitude of the AHP is directly proportional to the cytosolic calcium change during the action potential. However, the maximum change of cytosolic calcium that we have measured during a N1E-115 action potential is ca. $4 \mathrm{nM}$, whereas in a variety of preparations, $\mathrm{Ca}^{2+}$-gated $\mathrm{K}^{+}$channels are activated by cytosolic calcium in the micromolar range (Barrett et al., 1982; Gallin, 1984; Meech, 1978; Moczydlowski and Latorre, 1983). Since the small change obtained in N1E-1 15 cells reflects the average rise in $\left[\mathrm{Ca}^{2+}\right]_{\mathrm{i}}$ over the whole cell soma, our results suggest that most of the calcium ions that enter the cell soma during the action potential remain within a restricted region 
close to the membrane (Chad and Eckert, 1984). Within this restricted region the rise in calcium may be several orders of magnitude greater than the average rise in the entire soma.

During a train of action potentials, $\left[\mathrm{Ca}^{2+}\right]_{i}$ increases in a steplike fashion. However, under conditions that optimize calcium entry during a single action potential, repetitive stimulation at rates of $0.5 \mathrm{~Hz}$ or faster causes a decline in the calcium influx associated with successive action potentials, as well as in the amplitude and duration of these action potentials. Part of the depression of the calcium influx may result directly from inactivation of calcium channels. However, the progressive increase of $\left[\mathrm{Ca}^{2+}\right]_{\mathrm{i}}$ during the action potential train will also cause a progressive enhancement of the $\mathrm{Ca}^{2+}$-dependent $\mathrm{K}^{+}$conductance, thereby decreasing the amplitude and duration of the calcium component of the action potential. Therefore, part of the reduction of the $\left[\mathrm{Ca}^{2+}\right]_{i}$ change with repetitive stimulation may be an indirect effect of the decreased amplitude and duration of the action potential.

The present experiments are the first direct measurements of voltage-gated calcium transients in the soma, neurite, and growth cone regions of a single neuron. The most significant finding of these experiments is that an action potential elicited in the cell soma causes an increase in cytosolic calcium in all three regions, the largest increase being in the growth cone. It is unlikely that calcium elevation in the neurite is a consequence of calcium diffusion from the soma or the growth cone, because diffusion of calcium within the cytoplasm is extremely restricted (Chad and Eckert, 1984; Harary and Brown, 1984; Smith and Zucker, 1980). Furthermore, as noted above, calcium entering the soma of N1E-115 cells appears to remain near its site of entry. Hence, our results are clear evidence that voltage-gated calcium channels are present in the membrane of all specialized regions of a cultured neuron.

If certain conditions are met, the absorbance change in a particular cell region $\left(\Delta A_{660}\right)$ during an action potential is directly proportional to the calcium influx per unit area of membrane and depends on neither the total area studied nor the pathlength. These conditions are (1) [AIII] and $\left[\mathrm{Mg}^{2+}\right]$ are identical in the three regions; (2) the calcium concentration change in one region is produced only by calcium entering the cell through the membrane directly below or above this region; (3) the cell membrane density in the measurement area - that is, the ratio of cell membrane area to the cross-sectional area of the measurement beamis similar in the three regions; (4) the action potential has a similar amplitude and time course in all three regions; and (5) the ability of the cytosol to buffer calcium is identical in the three regions.

As noted in the introduction, the linearity of the AIII response means that changes in dye absorption are independent of the spatial distribution of the calcium added to a volume of dye. This is in contrast to the response of the photoprotein aequorin to the addition of an aliquot of calcium, which is greater when the calcium remains spatially restricted within the cell volume (Smith and Zucker, 1980). With AIII, we can consider, therefore, the simplest case in which calcium entering a region of a cell under study distributes uniformly throughout that region to increase the calcium concentration by $\Delta\left[\mathrm{Ca}^{2+}\right]$. We can write

$$
\begin{aligned}
& \Delta \mathrm{A}_{660} \propto \Delta\left[\mathrm{Ca}^{2+}\right] \times d \\
& \Delta\left[\mathrm{Ca}^{2+}\right] \propto \phi \times A / V
\end{aligned}
$$

where $d$ is the path length; $\phi$, the calcium influx per unit area of membrane; $A$, the membrane area; and $V$, cytosol volume. However,

$$
V \propto A \times d
$$

with the constant of proportionality being the same in all three regions of the cell if condition (3) is valid. Therefore,

$$
\Delta A_{660} \propto \phi \times A \times d / V \propto \phi
$$

Thus, the absorbance change during an action potential in a particular cell region is proportional to the density of activated calcium channels in the membrane of that region. Conditions (1) and (2) are likely to be valid (Chad and Eckert, 1984; Harary and Brown, 1984; Smith and Zucker, 1980). Conditions (3) and (4) also appear to be valid. The membrane of all three areas is free from obvious clefts and infoldings (Anglister et al., 1982; Graham et al., 1974); save at the highly motile ruffled edge of the growth cone, which was excluded from measurements by the rectangular aperture. The neurites and growth cones that we studied were considerably closer to the soma than the $900 \mu \mathrm{m}$ length constant of N1E-115 cells (Grinvald et al., 1981); thus the three regions are likely to be equipotential. With regard to condition (5), Tillotson and Gorman (1980) have shown that cytoplasmic calcium buffering capacity changes along the radial dimension within a molluscan neuron. However, no information is available as to the relative buffering capacity of the soma, neurite, and growth cone regions of a single neuron. Even if regional differences in buffering capacity do exist, it is extremely unlikely that they alone can account for the small absorbance change in the neurite region of N1E-115 cells. In fact, although calcium action potentials can be elicited by stimulation of either the soma or the growth cone, the neurite of N1E-115 cells is incapable of initiating calcium action potentials (Grinvald and Farber, 1981). Thus, it seems safe to conclude that the similarly large absorbance changes recorded from the soma and growth cone during an action potential indeed reflect the higher concentration of calcium channels in the membrane of these two regions, and the significantly smaller absorbance change recorded from the neurite is the consequence of a significantly lower density of calcium channels in the neurite membrane.

The above conclusions are in accordance with the widely accepted idea that calcium channels are concentrated in the neuronal soma and presynaptic terminal and that these two regions are capable of calcium-dependent electrical excitation. They also corroborate results obtained by indirect recordings of calcium action potentials in cultured neurons suggesting that early in neuronal development calcium action potential generation becomes confined to the soma and growth cone regions (Anglister et al., 1982; Dichter and Fischbach, 1977; Grinvald and Farber, 1981; Willard, 1980). However, the tentative conclusion that active calcium channels may therefore be absent from the neurites (Grinvald and Farber, 1981) is at odds with the present results, which clearly demonstrate the presence of active calcium channels in the neurite. Although their low density suggests that calcium contributes comparatively little to electrical excitability in this region, localized entry of calcium into the neurite might contribute significantly to several important functions. For example, neurites are packed with microtubules (Marchisio et al., 1978; Yamada et al., 1970) whose assembly and disassembly appear to be regulated by calcium and calmodulin (Schliwa et al., 1981). In addition, recent evidence indicates that calcium regulates a whole range of microfilament-based cell motility phenomena (Jacobs, 1982; Weeds, 1982), including organelle transport in the axon (Brady et al., 1984). Voltage-gated calcium channels in specific locations along the neurite might have far-reaching implications for these and other processes that involve the nerve cell cytoskeleton.

\section{References}

Ahmed, Z., and J. A. Connor (1979) Measurements of calcium influx under voltage clamp in molluscan neurones using the metallochromic dye arsenazo III. J. Physiol. (Lond.) 286: 61-82.

Alvarez-Leefmans, F. T., and R. Miledi (1980) Voltage sensitive calcium entry in frog motoneurones. J. Physiol. (Lond.) 308: 241-257.

Anglister, L., I. C. Farber, A. Shahar, and A. Grinvald (1982) Localization of voltage-sensitive calcium channels along developing neurites: Their possible role in regulating neurite elongation. Dev. Biol. 94: 351-365. 
Barrett, J. N., K. L. Magleby, and B. S. Pallotta (1982) Properties of single calcium-activated potassium channels in cultured rat muscle. J. Physiol. (Lond.) 331: 211-230.

Baylor, S. M., W. K. Chandler, and M. W. Marshall (1982) Optical measurements of intracellular $\mathrm{pH}$ and magnesium in frog skeletal muscle fibers. J. Physiol. (Lond.) 331: 105-137.

Brady, S. T., R. J. Lasek, R. D. Allen, H. L. Lin, and T. P. Stossel (1984) Gelsolin inhibition of fast axonal transport indicates a requirement for actin microfilaments. Nature 310: 56-58.

Brown, J. E., L. B. Cohen, P. DeWeer, L. H. Pinto, W. N. Ross, and B. M. Salzberg (1975) Rapid changes of intracellular free calcium concentration. Biophys. J. 15: 1155-1160.

Brown, H. M., and B. Rydqvist (1981) Arsenazo III-Ca ${ }^{2+}$. Effect of $\mathrm{pH}$, ionic strength, and arsenazo III concentration on equilibrium binding evaluated with $\mathrm{Ca}^{2+}$ ion sensitive electrodes and absorbance measurements. Biophys. J. 36: 117-137.

Campbell, A. K. (1983) Intracellular Calcium. Its Universal Role as a Regulator, Wiley, New York.

Chad, J. E., and R. Eckert (1984) Calcium domains associated with individual channels can account for anomalous voltage relations of Ca-dependent responses. Biophys. J. 45: 993-999.

Dichter, M. A., and G. D. Fischbach (1977) The action potential of chick dorsal root ganglion neurones maintained in cell culture. J. Physiol. (Lond.) 267: 281-298.

Fishman, M. C., and I. Spector (1981) Potassium current suppression by quinidine reveals additional calcium currents in neuroblastoma cells. Proc. Natl. Acad. Sci. USA 78: 5245-5249.

Gallin, E. K. (1984) Calcium- and voltage-activated potassium channels in human macrophages. Biophys. J. 46: 821-825.

Gorman, A. L. F., and M. V. Thomas (1980) Intracellular calcium accumulation during depolarization in a molluscan neurone. J. Physiol. (Lond.) 308: 251-285.

Graham, D. I., N. K. Gonatas, and F. C. Charalampas (1974) The undifferentiated and extended forms of C1300 murine neuroblastoma. Am. J. Pathol. 76: 285-312.

Grinvald, A., and I. C. Farber (1981) Optical recording of $\mathrm{Ca}^{++}$action potentials from growth cones of cultured neurons with a laser microbeam. Science 212: 1164-1167.

Grinvald, A., W. N. Ross, and I. Farber (1981) Simultaneous optical measurements of electrical activity from multiple sites on processes of cultured neurons. Proc. Natl. Acad. Sci. USA 78: 3245-3249.

Hagiwara, S., and L. Byerly (1981) Calcium channel. Annu. Rev. Neurosci. 4: 69-125.

Harary, H. H., and J. E. Brown (1984) Spatially nonuniform changes in intracellular calcium ion concentrations. Science 224: 292-294.

Hille, B. (1984) Ionic Channels in Excitable Membranes, Sinauer, Sunderland, MA.

Jacobs, M. (1982) Microfilament organization and cell movement. Trends Neurosci. 5: 369-373.

Kado, R. T. (1973) Aplysia giant cell: Soma-axon voltage clamp current differences. Science 182: 843-845.

Katz, B. (1969) The Release of Neurotransmitter Substances, Thomas, Springfield, IL.

Llinás, R., and M. Sugimori (1980) Electrophysiological properties of in vitro purkinje cell dendrites in mammalian cerebellar slices. J. Physiol. (Lond.) 305: 197-213.

Llinás, R., I. Z. Steinberg, and K. Walton (1981) Presynaptic calcium currents in squid giant synapse. Biophys. J. 33: 289-322.

Marchisio, P. C., M. Osboron, and K. Weber (1978) Changes in the intracellular organization of tubulin and actin in N18 neuroblastoma cells during the process of axon extension induced by serum deprivation. Brain Res. 155: 229-237.
Meech, R. W. (1978) Calcium-dependent potassium activation in nervous tissue. Annu. Rev. Biophys. Bioeng. 7:1-18.

Meves, H., and W. J. Vogel (1973) Calcium inward currents internally perfused giant axons. J. Physiol. (Lond.) 235: 225-265.

Miledi, R., and I. Parker (1981) Calcium transients recorded with arsenazo III in the presynaptic terminal of the squid giant synapse. Proc. R. Soc. London [Biol.] 212: 197-211.

Moczydlowski, E., and R. Latorre (1983) Gating kinetics of $\mathrm{Ca}^{++}$ activated $\mathrm{K}^{+}$channels from rat muscle incorporated into planar lipid bilayers: Evidence for two voltage-dependent $\mathrm{Ca}^{++}$binding reactions. J. Gen. Physiol. 82: 511-542.

Moolenaar, W. H., and I. Spector (1978) Ionic currents in cultured mouse neuroblastoma cells under voltage clamp conditions. J. Physiol. (Lond.) 278: 265-286.

Moolenaar,W. H., and I. Spector (1979a) The calcium action potential and a prolonged calcium-dependent after-hyperpolarization in mouse neuroblastoma cells. J. Physiol. (Lond.) 292: 297-306.

Moolenaar, W. H., and I. Spector (1979b) The calcium current and the activation of a slow potassium conductance in voltage-clamped mouse neuroblastoma cells. J. Physiol. (Lond.) 292: 307-323.

Moolenaar, W. H., L. G. J. Teroolen, and S. W. de Laat (1984) Phorbol ester and diacylglycerol mimic growth factors in raising cytoplasmic pH. Nature 312: 371-374.

Neering, I. R., and R. N. McBurney (1984) Role for microsomal Ca storage in mammalian neurones? Nature 309: 158-160.

Nirenberg, M., S. Wilson, H. Higashida, A. Rotter, K. Krueger, N. Busis, R. Ray, J. G. Kenimer, and M. Adler (1983) Modulation of synapse formation by cyclic adenosine monophosphate. Science 222: 794799.

Ross, W. N., and A. E. Stuart (1978) Voltage sensitive calcium channels in the presynaptic terminals of a decrementally conducting photoreceptor. J. Physiol. (Lond.) 274: 173-191.

Schliwa, M., U. Euteneuer, J. C. Bulinski, and J. G. Iznat (1981) Calcium lability of cytoplasmic microtubules and its modulation by microtubule-associated proteins. Proc. Natl. Acad. Sci. USA 78: $1037-$ 1041 .

Smith, S. J., and R. S. Zucker (1980) Aequorin response facilitation and intracellular calcium accumulation in molluscan neurones. $\mathrm{J}$. Physiol. (Lond.) 300: 167-196.

Smith, S. J., A. B. MacDermott, and F. F. Weight (1983) Detection of intracellular $\mathrm{Ca}^{2+}$ transients in sympathetic neurones using arsenazo III. Nature 304: 350-352.

Spector, I., Y. Kimhi, and P. G. Nelson (1973) Tetrodotoxin and cobalt blockade of neuroblastoma action potentials. Nature [New Biol.] 246: 124-126.

Stockbridge, N., and W. N. Ross (1984) Localized $\mathrm{Ca}^{2+}$ and calciumactivated potassium conductances in terminals of a barnacle photoreceptor. Nature 309: 266-268.

Tillotson, D., and A. L. F. Gorman (1980) Non-uniform $\mathrm{Ca}^{2+}$ buffer distribution in a nerve cell body. Nature 286:816-817.

Weeds, A. (1982) Actin-binding proteins-regulators of cell architecture and motility. Nature 296:811-816.

Willard, A. L. (1980) Electrical excitability of outgrowing neurites of embryonic neurons in cultures of dissociated neural plate of Xenopus laevis. J. Physiol. (Lond.) 301: 115-128.

Yamada, K. M., B. S. Spooner, and N. K. Wessels (1970) Axon growth: Roles of microfilaments and microtubules. Proc. Natl. Acad. Sci. USA 66: 1206-1212.

Yellen, G. (1982) Single $\mathrm{Ca}^{2+}$-activated nonselective cation channels in neuroblastoma. Nature 296: 357-359. 